International Journal of Engineering, Science and Technology Vol. 4, No. 1, 2011, pp. 23-37

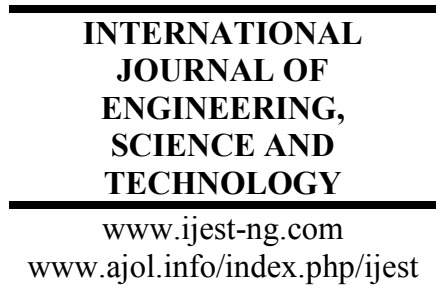

(C) 2012 MultiCraft Limited. All rights reserved

\title{
Load frequency control of three area interconnected hydro-thermal reheat power system using artificial intelligence and PI controllers
}

\author{
Surya Prakash $^{1 *}$, S.K. Sinha ${ }^{2}$ \\ I* Department of Electrical \& Electronics Engineering, Shepherd School of Engineering \& Technology, \\ Sam Higginbottom Institute of Agriculture, Technology \& Sciences- Deemed University, Allahabad, INDIA \\ ${ }^{2}$ Department of Electrical Engineering, Kamala Nehru Institute of Technology, Sultanpur-UP, INDIA, \\ ${ }^{*}$ Corresponding Author Email-sprakashgiri0571@yahoo.com, Phone: 09956722055
}

\begin{abstract}
This paper present analysis on dynamic performance of Load Frequency Control (LFC) of three area interconnected hydrothermal reheat power system by the use of Artificial Intelligent and PI Controller. In the proposed scheme, control methodology developed using conventional PI controller, Artificial Neural Network (ANN) and Fuzzy Logic controller (FLC) for three area interconnected hydro-thermal reheat power system. In this paper area-1 and area- 2 consists of thermal reheat power plant whereas area-3 consists of hydro power plant. In this proposed scheme, the combination of most complicated system like hydro plant and thermal plant with reheat turbine are interconnected which increases the nonlinearity of the system. The performances of the controllers are simulated using MATLAB/SIMULINK package. A comparison of PI controller, Fuzzy controller and ANN controller based approaches shows the superiority of proposed ANN based approach over Fuzzy and PI for same conditions. To enhance the performance of PI, Fuzzy and neural controller sliding surface is included. The simulation results also tabulated as a comparative performance in view of settling time and peak over shoot.
\end{abstract}

Keywords : Load Frequency Control (LFC), Fuzzy Logic Controller, ANN Controller, PI controller, Area Control Error (ACE), Tie-line, MATLAB / SIMULINK.

DOI: http://dx.doi.org/10.4314/ijest.v4i1.4S

\section{Introduction}

Automatic Generation Control (AGC) or Load Frequency Control is a very important issue in power system operation and control for supplying sufficient and reliable electric power with good quality. AGC is a feedback control system adjusting a generator output power to remain defined frequency. The interconnected power system is divided into three control areas, all generators are assumed to form a coherent group (Grass G et al, 2001). Load Frequency Control (LFC) is being used for several years as part of the Automatic Generation Control (AGC) scheme in electric power systems. One of the objectives of AGC is to maintain the system frequency at nominal value $(50 \mathrm{hz})$. In the steady state operation of power system, the load demand is increased or decreased in the form of Kinetic Energy stored in generator prime mover set, which results the variation of speed and frequency accordingly. Therefore, the control of load frequency is essential to have safe operation of the power system (Kothari D.P et al, 2003), (Kundur P, 1994), (Wadhawa CL, 2007), (Elgerd O.I, 1971).

A control strategy is needed that not only maintains constancy of frequency and desired tie-power flow but also achieves zero steady state error and inadvertent interchange. Among the various types of load frequency controllers, the most widely employed is the conventional proportional integral (PI) controller. The PI controller is very simple for implementation and gives better dynamic response, but their performances deteriorate when the complexity in the system increases due to disturbances like load variation boiler dynamics (Talaq J et al, 1999), (Arvindan P et al, 2009). Therefore, there is need of a controller which can overcome this problem. The Artificial Intelligent controllers like Fuzzy and Neural control approaches are more suitable in this respect. Fuzzy 
system has been applied to the load frequency control problems with rather promising results (Nanda J et al, 2003). The salient feature of these techniques is that they provide a model- free description of control systems and do not require model identification.

Literature survey shows that most of earlier work in the area of LFC pertains to interconnected thermal system and relatively lesser attention has been devoted to the LFC of three area interconnected hydro-thermal system (Arvindan P et al, 2009). The fuzzy controller offers better performance over the conventional controllers, especially, in complex and nonlinearities associated system. (Magla A et al, 2004) applied Fuzzy Controller to the two region interconnected reheat thermal and hydro power system. However, it is demonstrated good dynamics only when selecting the specific number of membership function, so that the method had limitation. To over come this Artificial Neural Network (ANN) controller, which is an advance adaptive control configuration, is used because the controller provides faster control than the others (Demiroren et al., 2001). In this paper, the performance evaluation based on PI controller, Fuzzy controller and Artificial Neural controller for three area interconnected thermal-hydro power plant is proposed. The sliding concept arises due to variable structure concept. The objective of VSC has been greatly extended from stabilization to other control functions. The most distinguished feature of VSC is its ability to result in very robust control systems; in many cases invariant control system result. The term 'invariant' means that the system is completely insensitive to parametric uncertainty and external disturbances (John et al., 1993; Kumar et al., 1985).

\section{The Power System Investigated}

The detailed designed model of three area hydro-thermal power system for load frequency control investigated is shown in Figure 1. An extended power system can be divided into a number of load frequency control areas interconnected by means of tie lines. Without loss of generality one can consider a three- area case connected by tie lines (Prakash et al., 2009).

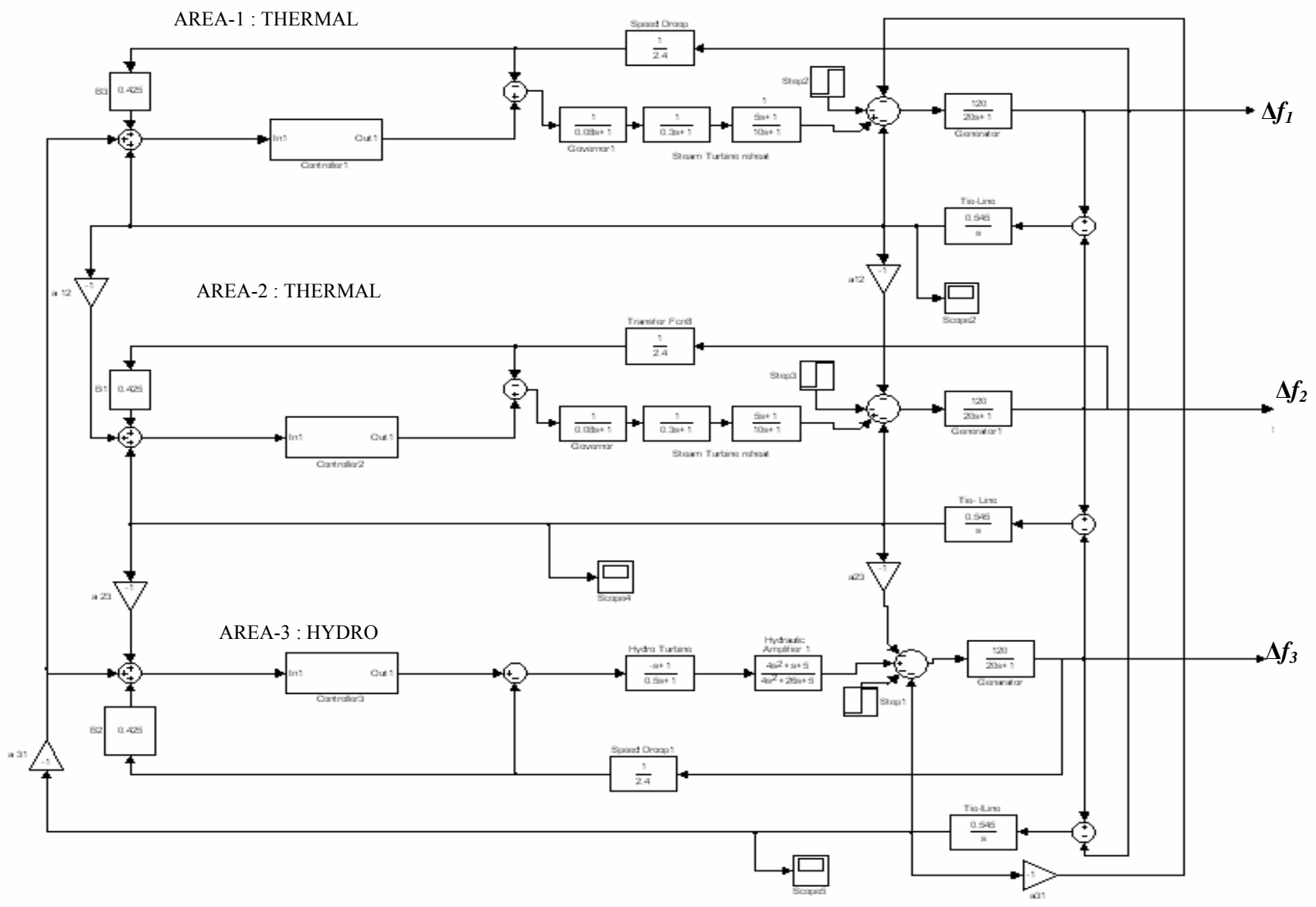

Fig. 1. MATLAB Model of three area hydro-thermal reheat power system. 
The control objectives are as follows:

(i) Each control area as for as possible should supply its own load demand and power transfer through tie line should be on mutual agreement.

(ii) All control areas should controllable to the frequency control.

In an isolated control area case the incremental power $\left(\Delta P_{G}-\Delta P_{D}\right)$ was accounted for by the rate of increase of stored kinetic energy and increase in area load caused by increase in frequency. The Transfer Functions of different blocks used in power system model are given below:

Transfer function (T/F) of hydraulic Turbine is $\frac{-T w \cdot s+1}{0.5 T w \cdot s+1}$

$\mathrm{T} / \mathrm{F}$ of hydraulic Governor is $\quad \frac{K d \cdot s^{2}+K p \cdot s+K i}{K d . s^{2}+\left(K p+f / R_{2}\right) s+K i}$

$\mathrm{T} / \mathrm{F}$ of governor (thermal plant) is $\frac{1}{T g \quad s+1}$

$\mathrm{T} / \mathrm{F}$ of steam turbine is $\quad \frac{K r \cdot T r \cdot s+1}{\operatorname{Tr} . s+1}$

$\mathrm{T} / \mathrm{F} \quad$ of Re-heater is $\frac{1}{T t \cdot s+1}$

And transfer function of Generator is $\frac{K p}{T p \cdot s+1}$

\subsection{Modeling of Tie-Line}

The power transfer equation through tie line is,

$$
P_{12}=\frac{\left|V_{1}\right|\left|V_{2}\right|}{x} \sin \left(\delta_{1}-\delta_{2}\right)
$$

Considering area 1 has surplus power and transfers to area 2

$\mathrm{P}_{12}=$ Power transferred from area 1 to 2 through tie line.

$$
P_{12}=\frac{\left|\mathrm{V}_{1}\right| \cdot\left|\mathrm{V}_{2}\right|}{\mathrm{X}_{12}} \cdot \operatorname{Sin}\left(\delta_{1} 1-\delta 2\right)
$$

Where

$\delta_{1}, \delta_{2}$ and $\delta_{3}=$ Power angles of end voltages $\mathrm{V}_{1}, \mathrm{~V}_{2}$ and $\mathrm{V}_{3}$ of equivalent machine of the three areas respectively.

$\mathrm{X}_{12}=$ reactance of tie line.

The order of the subscripts indicates that the tie line power is define positive in direction 1 to 2 . For small deviation in the angles and the tie line power changes with the amount i.e. small deviation in $\delta_{1}, \delta_{2}$ and $\delta_{3}$ changes by $\Delta \delta 1, \Delta \delta 2$, and ${ }_{\Delta} \delta_{3}$ respectively.

Power $\mathrm{P}_{12}$ changes to $\mathrm{P}_{12}+\Delta P_{12}$

Therefore, Power transferred from Area 1 to Area 2 as given in [11] is

$$
\Delta P_{12}(s)=\frac{2 \pi T^{o}}{s}\left(\Delta f_{1}(s)-\Delta f_{2}(s)\right)
$$

$\mathrm{T}^{0}=$ Torque produced

The above equation can be represented as in Fig. 2 


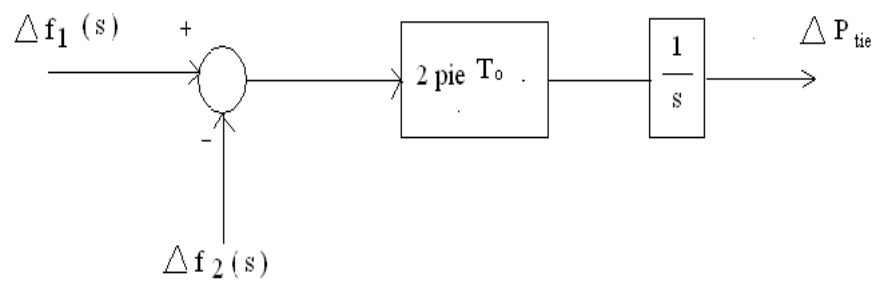

Fig. 2 : Block Diagram Representation of a Tie -Line

\subsection{Tie Line Control}

In normal operation the power on the tie-line follows from the equation i.e.

$$
\begin{aligned}
{\left[\Delta P_{T 1}(s)-\Delta P_{E 1}(s)-\Delta P_{12}(s)\right] } & =\frac{2 H_{1}}{f_{o}} s \Delta f_{1}(s)+B_{1} \Delta f_{1}(s) \\
& =\frac{2 H_{1}}{f_{0}} \Delta f_{1}(s) B_{1}\left[\frac{1}{B_{1}} s+1\right]
\end{aligned}
$$

$$
\text { If } \begin{gathered}
\frac{2 H_{1} B_{1}}{f_{o}}=\frac{1}{K_{P 1}} \\
\frac{1}{B_{1}}=T_{P 1}
\end{gathered}
$$

Equation (4) can be written as

$$
\begin{gathered}
\Delta f_{1}(s)=G_{P 1}(s)\left[\Delta P_{T 1}(s)-\Delta P_{E 1}(s)-\Delta P_{12}(s)\right] \\
G_{P 1}(s)=\frac{K_{P 1}}{1+s T_{P 1}} \\
\Delta P_{12}=\Delta \mathrm{P}_{21}=\Delta \mathrm{P}_{31}
\end{gathered}
$$

Where $\Delta P_{E} \quad$ is the real load change

Due to the action of turbine controllers, the generator increases its output by the amount $\Delta P_{T}$.

The net surplus power $\Delta P_{T}-\Delta P_{E}$ will be absorbed by the system.

Tie-line bias control is used to eliminate steady state error in frequency in tie-line power flow. This states that the each control area must contribute their share to frequency control in addition for taking care of their own net interchange.

Let $\quad \mathrm{ACE}_{1}=$ area control error of area 1

$\mathrm{ACE}_{2}=$ Area control error of area 2

$\mathrm{ACE}_{3}=$ Area control error of area 3

In this control, $\mathrm{ACE}_{1}, \mathrm{ACE}_{2}$ and $\mathrm{ACE}_{3}$ are made linear combination of frequency and tie line power error (Prakash $\mathrm{S}$ et al, 2009).

$$
\begin{aligned}
& \mathrm{ACE}_{1}=\Delta P_{12}+\mathrm{b}_{1} \Delta f_{1} \\
& \mathrm{ACE}_{2}=\Delta P_{21}+\mathrm{b}_{2} \Delta f_{2}
\end{aligned}
$$




$$
\mathrm{ACE}_{3}=\Delta P_{31}+\mathrm{b}_{3} \Delta f_{3}
$$

Where the constant $\mathrm{b}_{1}, \mathrm{~b}_{2} \& \mathrm{~b}_{2}$ are called area frequency bias of area 1 , area 2 and area 3 respectively. Now $\triangle P R_{1}, \triangle P R_{2}$ and $\triangle P R_{3}$ are mode integral of $\mathrm{ACE}_{1}, \mathrm{ACE}_{2}$ and $\mathrm{ACE}_{3}$ respectively.

$$
\begin{aligned}
& \Delta P R_{1}=-\mathrm{K}_{\mathrm{i} 1} \int_{0}^{\mathrm{t}}\left(\Delta \mathrm{P}_{12}+b_{1} \Delta f_{1}\right) d t \\
& \Delta P R_{2}=-\mathrm{K}_{\mathrm{i} 2} \int_{0}^{\mathrm{t}}\left(\Delta \mathrm{P}_{21}+b_{2} \Delta f_{2}\right) d t \\
& \Delta P R_{3}=-\mathrm{K}_{\mathrm{i} 3} \int_{0}^{\mathrm{t}}\left(\Delta \mathrm{P}_{13}+b_{3} \Delta f_{3}\right) d t \\
& \Delta P_{12}=\Delta P_{\text {tie, }, 1}, \Delta P_{21}=\Delta P_{\text {tie }, 2} \text { and } \Delta P 3_{1}=\Delta P_{\text {tie }, 3}
\end{aligned}
$$

Therefore $\frac{\Delta P_{\text {tie }, 1}}{\Delta P_{\text {tie }, 2}}=-\frac{\mathrm{T}_{12}}{\mathrm{~T}_{21}}=-\frac{1}{\mathrm{a}_{2}}=$ constant

Hence $\Delta P_{\text {tie }, 1}=\Delta P_{\text {tie }, 2}=\Delta P_{\text {tie }, 3}=0$

$$
\triangle P R_{1}=\Delta P R_{2}=\Delta P R_{3} \text {, }
$$

And $\Delta f_{1}=\Delta f_{2}=\Delta f_{3}=0$

Thus, under steady condition change in the tie- line power and frequency of each area is zero. This has been achieved by integration of ACEs in the feedback loops of each area (Kothari D P et al, 2003). Control methodology used (FLC, ANN and PI) is mentioned in the next preceeding sections.

\section{Control Methodology}

\subsection{PI Controller}

One of the most widely used control laws in thermal and hydro power station governing systems is the PI type controller. Proportional controller is used to reach the steady state condition much quicker because of the faster transient response with proportional controller. The proportional term of the controller produces a control signal proportional to the error in the system, so that $\mathrm{u}(\mathrm{t})=K \mathrm{p}$ e (t). Typically, given a step change of load demand, low values of $K \mathrm{p}$ give rise to stable responses with large steady-state errors. Higher values of $K \mathrm{p}$ give better steady-state performance, but worse transient response. Therefore, the higher value of $K \mathrm{p}$ is used to reduce the steady state error, although increasing the gain $K \mathrm{p}$ decreases the system time constant and damping. Therefore it is evident to choose the optimum value of $K \mathrm{p}$. The proportional action can never eliminate the steady state error in the system because some (small) error must be present in order to produce a control output. A common way of reducing the steady state error is by incorporating integral action into the controller. Here, the control signal generated is proportional to the integral of the error signal, that is,

$$
u(t)=\kappa_{\mathrm{i}} \int e(t) d t
$$

Where $\mathrm{Ki}$ is the integral gain. While an error exists, the integrator tends to increase control action, thus driving the plant output towards the demand output. Then, when the error disappears, the continuing integrator output can be used to maintain the control action necessary for steady-state conditions. But, if the gain of integrator $K \mathrm{i}$ is sufficiently high, overshoot will occur increasing sharply as a function of the gain, this is highly undesirable. Lower value of $K$ i reduces overshoot but increases rise time of the system. Based upon discussion it is required to design both the $K \mathrm{p}$ and $K \mathrm{i}$ properly (Chatterjee K, 2010).

\subsection{Fuzzy Logic Controller}

Fuzzy logic is a thinking process or problem-solving control methodology incorporated in control system engineering, to control systems when inputs are either imprecise or the mathematical models are not present at all. Fuzzy logic can process a reasonable number of inputs but the system complexity increases with the increase in the number of inputs and outputs, therefore distributed processors would probably be easier to implement. Fuzzification is process of making a crisp quantity into the fuzzy (Ross T J, 1995). They carry considerable uncertainty. If the form of uncertainty happens to arise because of imprecision, ambiguity, or vagueness, then the variable is probably fuzzy and can be represented by a membership function. 
Defuzzification is the conversion of a fuzzy quantity to a crisp quantity, just as fuzzification is the conversion of a precise quantity to a fuzzy quantity. There are many methods of defuzzification, out of which smallest of maximum method is applied in making fuzzy inference system (Prakash S et al, 2009). The Fuzzy logic control consists of three main stages, namely the fuzzification interface, the inference rules engine and the defuzzification interface (Ha Q P, 1998). For Load Frequency Control the process operator is assumed to respond to variables error $(e)$ and change of error $(c e)$. The fuzzy logic controller with error and change in error is shown in fig. 3.

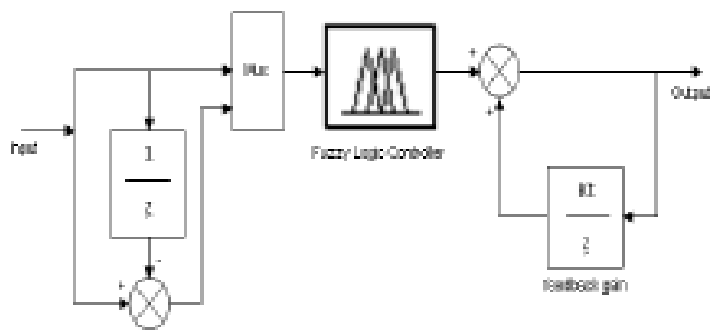

Fig.3 Fuzzy Logic Controller

The variable error is equal to the real power system frequency deviation $(\Delta f)$. The frequency deviation $\Delta f$, is the difference between the nominal or scheduled power system frequency $\left(f_{\mathrm{N}}\right)$ and the real power system frequency $(f)$. Taking the scaling gains into account, the global function of the FLC output signal can be written as.

$\Delta P c=F\left[n_{c} \mathrm{e}(\mathrm{k}), \quad \mathrm{n}_{\text {ce }} \operatorname{ce}(\mathrm{k})\right]$

Where $n_{e}$ and $n_{c e}$ are the error and the change in error scaling gains, respectively, and $F$ is a fuzzy nonlinear function. FLC is dependant to its inputs scaling gains (Ha Q P, 1998). A label set corresponding to linguistic variables of the input control signals, $e(k)$ and ce(k), with a sampling time of $0.01 \mathrm{sec}$ is given Attempt has been made to examine with Seven number of triangular membership function (MFs) namely Negative Big(NB), Negative Medium(NM), Negative Small(NS), Zero(ZO), Positive Small(PS), Positive Medium(PM) and Positive Big(PB) are used. The range on input (error in frequency deviation and change in frequency deviation) i.e universe of discourse is -0.25 to 0.25 and -0.01 to 0.01 . The numbers of rules are 49 . The membership functions (MFs) for the input variables are shown in Fig.4.

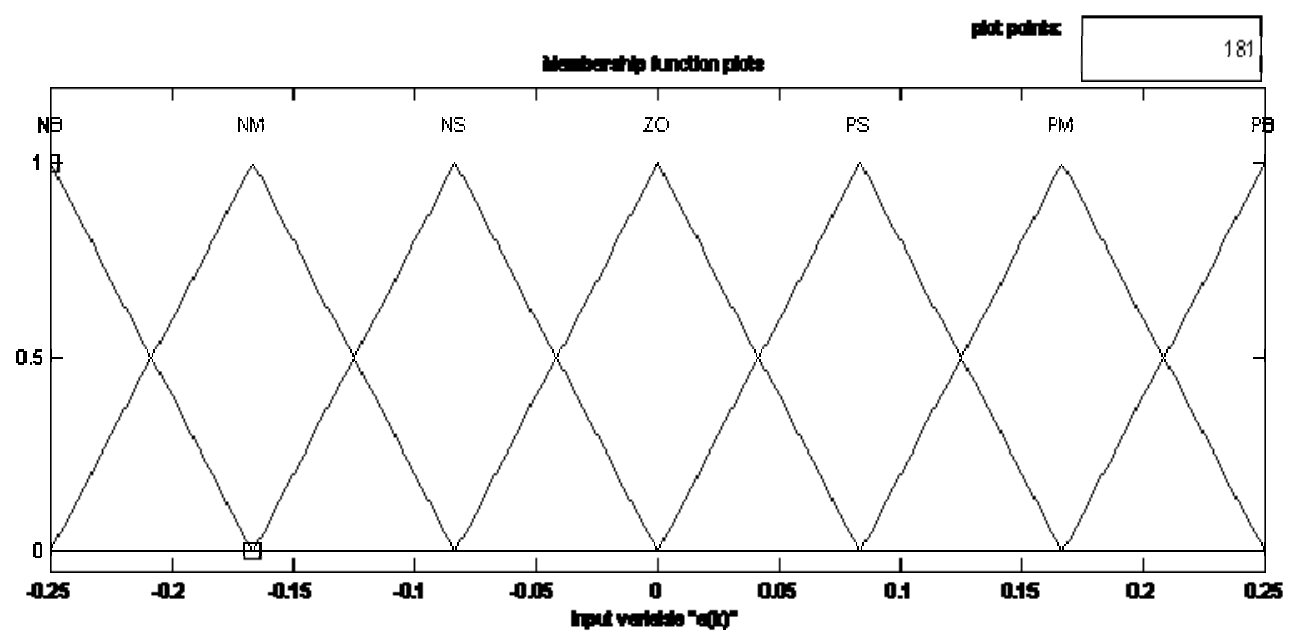

Fig.4. Membership Function for the control input variables 
Table 1. Fuzzy Inference Rule for Fuzzy Logic Controller

\begin{tabular}{|c|c|c|c|c|c|c|c|c|}
\hline Input & \multicolumn{7}{|c|}{$e(k)$} \\
\hline \multirow{5}{*}{$c e(k)$} & & NB & NM & NS & ZO & PS & PM & PB \\
\cline { 2 - 9 } & NB & PB & PB & PB & PB & PM & PM & PS \\
\cline { 2 - 9 } & NM & PB & PM & PM & PM & PS & PS & PS \\
\cline { 2 - 9 } & ZO & NS & NS & NS & ZO & PS & PS & PS \\
\cline { 2 - 9 } & PS & ZO & NS & NS & NS & NS & NM & NM \\
\cline { 2 - 9 } & PM & NS & NS & NM & NM & NM & NB & NB \\
\cline { 2 - 9 } & PB & NS & NM & NB & NB & NB & NB & NB \\
\hline
\end{tabular}

\subsection{Artificial Neural Network (ANN) Controller}

ANN is information processing system, in this system the element called as neurons process the information. The signals are transmitted by means of connecting links. The links process an associated weight, which is multiplied along with the incoming signal (net input) for any typical neural net. The output signal is obtained by applying activations to the net input. The field of neural networks covers a very broad area (Hykin S, 1994) (Mines JN, 1997). A neuron has more than one input. A neuron with inputs is shown in Fig.5. The individual inputs $p_{1,} p_{2, \ldots} p_{R}$ are each weighted by corresponding elements $\mathrm{w}_{1,1}, \mathrm{w}_{1,2}, \ldots \mathrm{w}_{1, \mathrm{R}}$ of the weight matrix $W$. The neuron has a bias $b$, which is summed with the weighted inputs to form the net input $\mathrm{n}$.

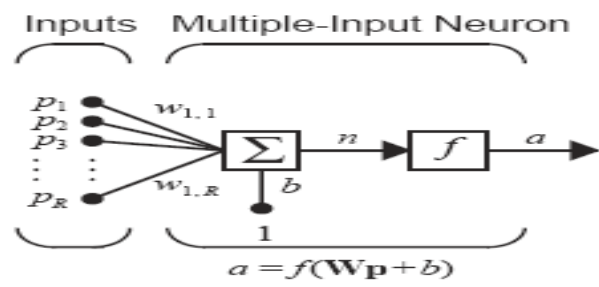

Fig. 5 Multi input neuron model

$$
n=w_{1,1} p_{1}+w_{1,2} p_{2}+\cdots+w_{1, R} p_{R}+b .
$$

This expression can be written in matrix form:

$$
n=\mathbf{W}_{\mathbf{p}}+b,
$$

Where the matrix $\mathrm{W}$ for the single neuron case has only one row.Now the neuron output can be written as

$$
a=f(\mathbf{W} \mathbf{p}+b) .
$$

The log-sigmoid transfer function is commonly used in multilayer networks that are trained using the back propagation algorithm, in part because this function is differentiable.

\subsection{NARMA-L2 Controller}

The ANN controller architecture employed here is a Non linear Auto Regressive Model reference Adoptive Controller. This controller requires the least computation of the three architectures. This controller is simply a rearrangement of the neural 
network plant model, which is trained offline, in batch form. It consists of reference, plant out put and control signal. The controller is adaptively trained to force the plant output to track a reference model output. The model network is used to predict the effect of controller changes on plant output, which allows the updating of controller parameters. In the study, the frequency deviations, tie-line power deviation and load perturbation of the area are chosen as the neural network controller inputs (Hykin S, 1994).

The outputs of the neural network are the control signals, which are applied to the governors in the area. The data required for the ANN controller training is obtained from the designing the Reference Model Neural Network and applying to the power system with step response load disturbance. NARMA-L2 ANN controller is shown in fig. 6.

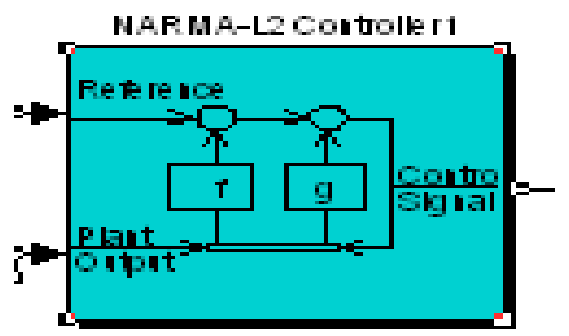

Fig. 6 NARMA-L2 Contoller

After a series of trial and error and modifications, the ANN architecture provides the best performance. It is a three-layer perceptron with five inputs, 13 neurons in the hidden layer, and one output in the ANN controller. Also, in the ANN plant model, it is a three-layer perceptron with four inputs, 10 neurons in the hidden layer, and one output. The activation function of the networks neurons is trainlm function.300 training sample has been taken to train 300 no of epochs. The proposed network has been trained by using the learning performance. Learning algorithms causes the adjustment of the weights so that the controlled system gives the desired response.

\section{Simulation and Results}

In this presented work, three areas hydro-thermal reheat interconnected power system have been developed with PI, fuzzy logic and ANN controllers to illustrate the performance of load frequency control using MATLAB/SIMULINK package. The parameters used for simulation are given in appendix (Magla A et al, 2004). Three types of simulink models are developed with PI, fuzzy and ANN controllers to obtain better dynamic behavior.

Refer to Simulink models, frequency deviation plots for thermal, and hydro cases are obtained separately for $1 \%$ step load change in system frequency and tie-line power as shown in fig. 7-20 respectively.

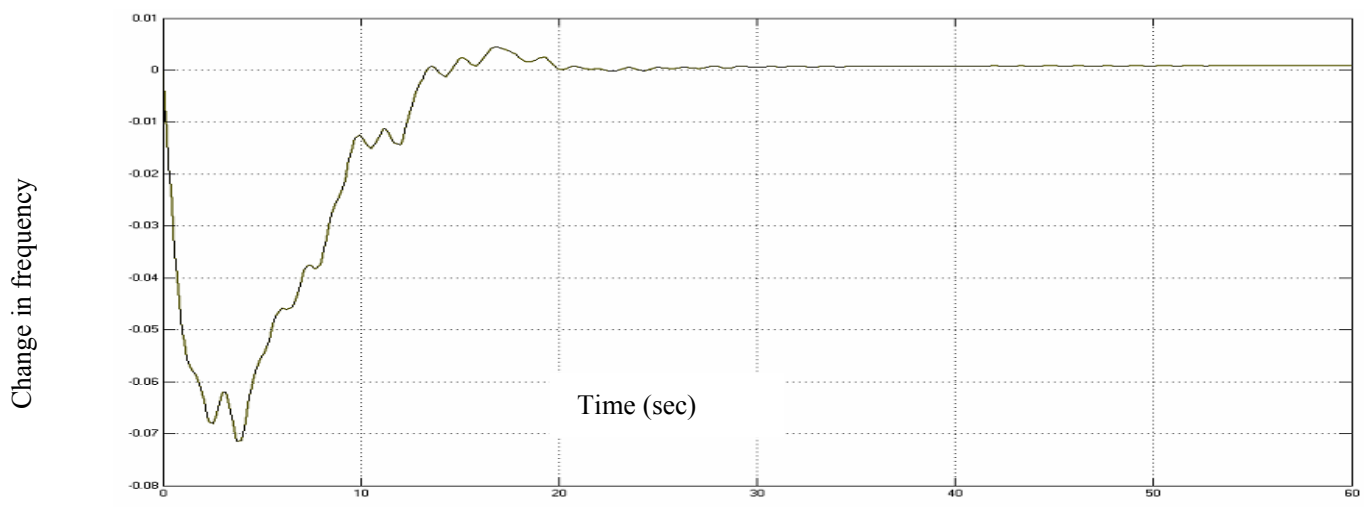

Fig. 7 Change in frequency (thermal plant) - with fuzzy controller $(\Delta f)$ 


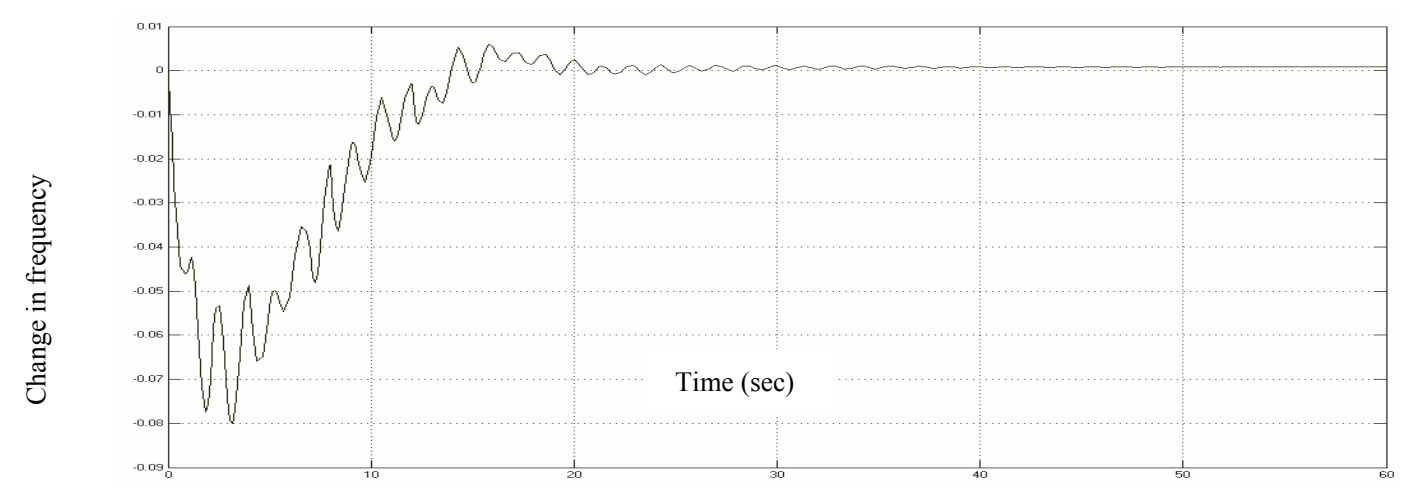

Fig. 8 Change in frequency (Hydro plant)- with fuzzy controller $(\Delta f)$

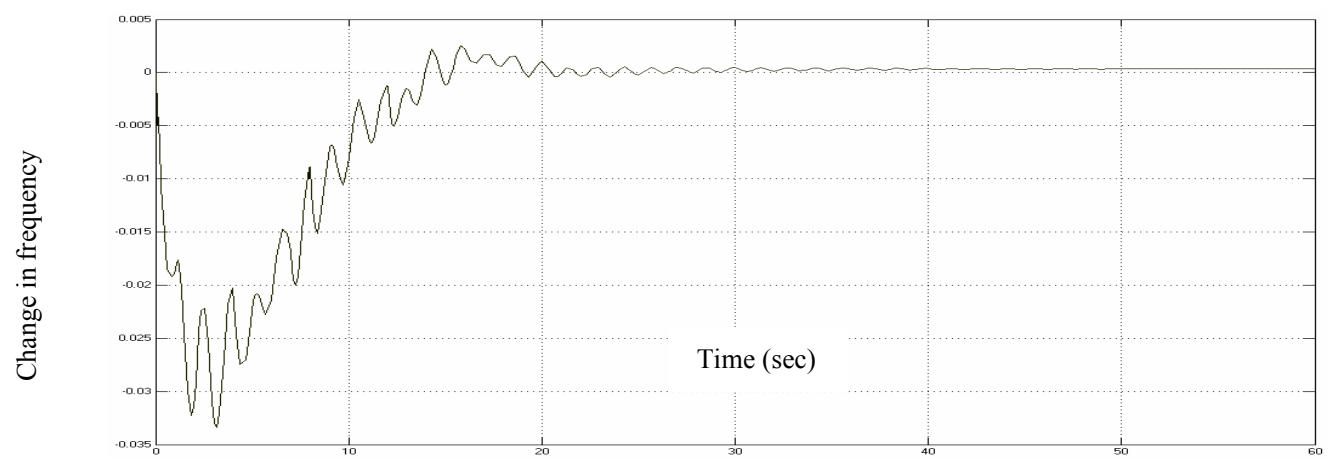

Fig. 9 Change in Tie-line power (hydro-thermal plant) with fuzzy control $\left(\Delta \mathrm{P}_{\text {tie }}\right)$

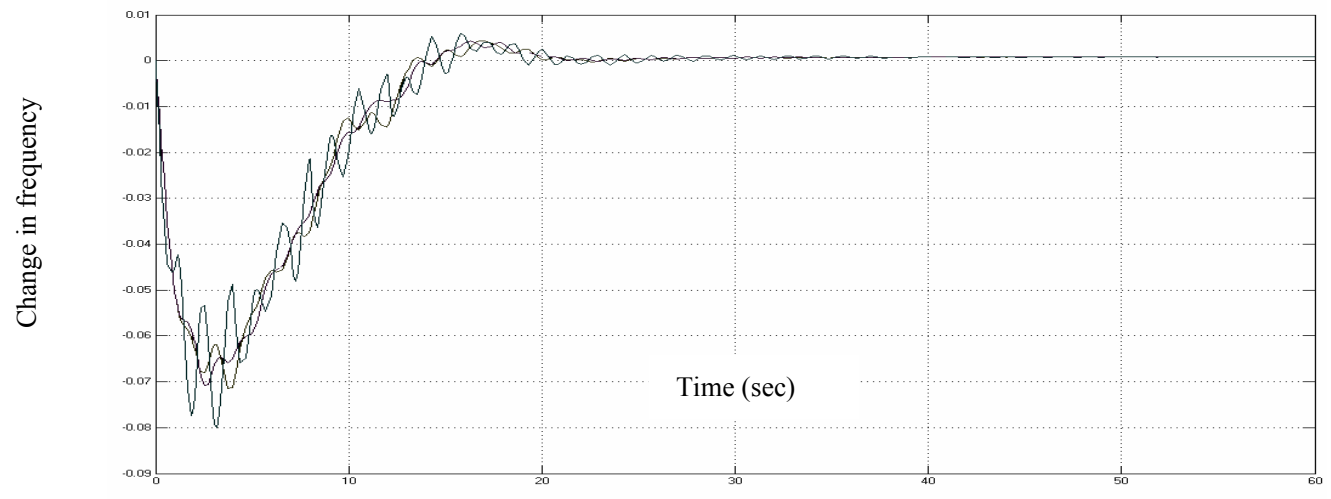

Fig. 10 Change in frequency (Hydro-thermal plant) with Fuzzy controller $(\Delta f)$.

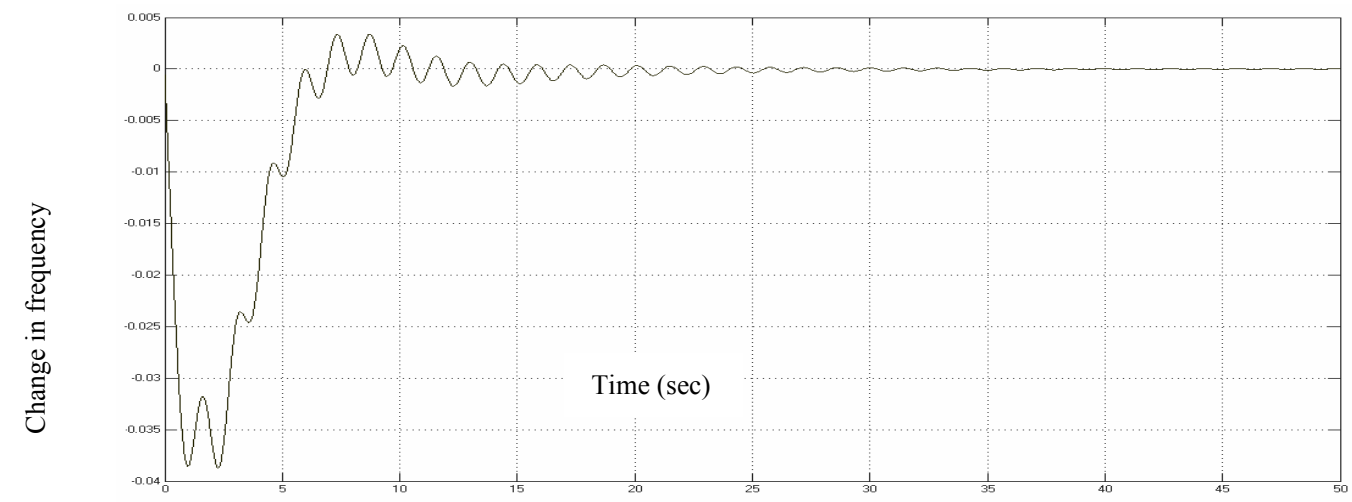

Fig.11. Change in frequency (Thermal plant) with ANN controller $(\Delta f)$.. 


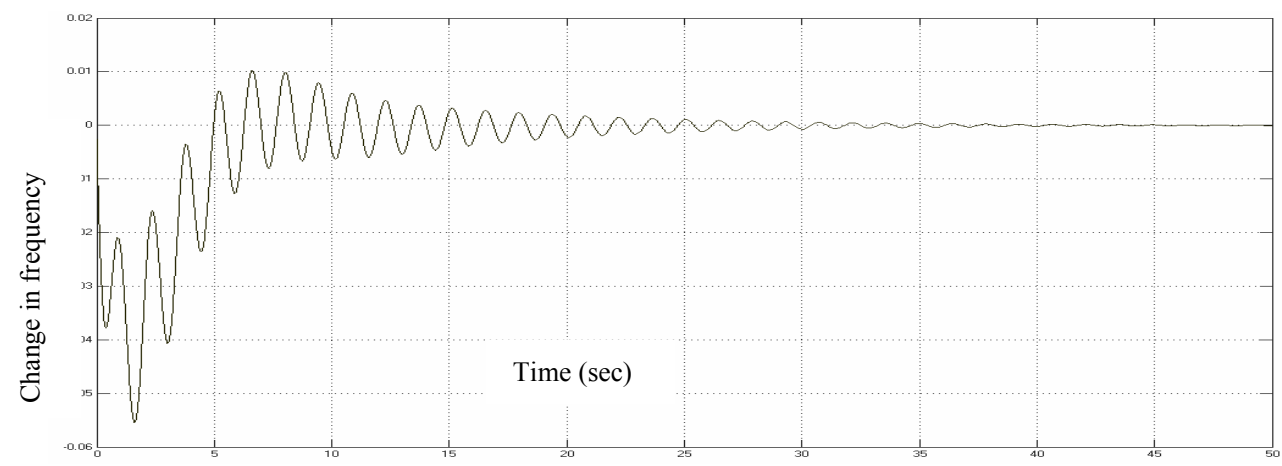

Fig. 12 Change in frequency (hydro plant) with ANN controller $(\Delta f)$.

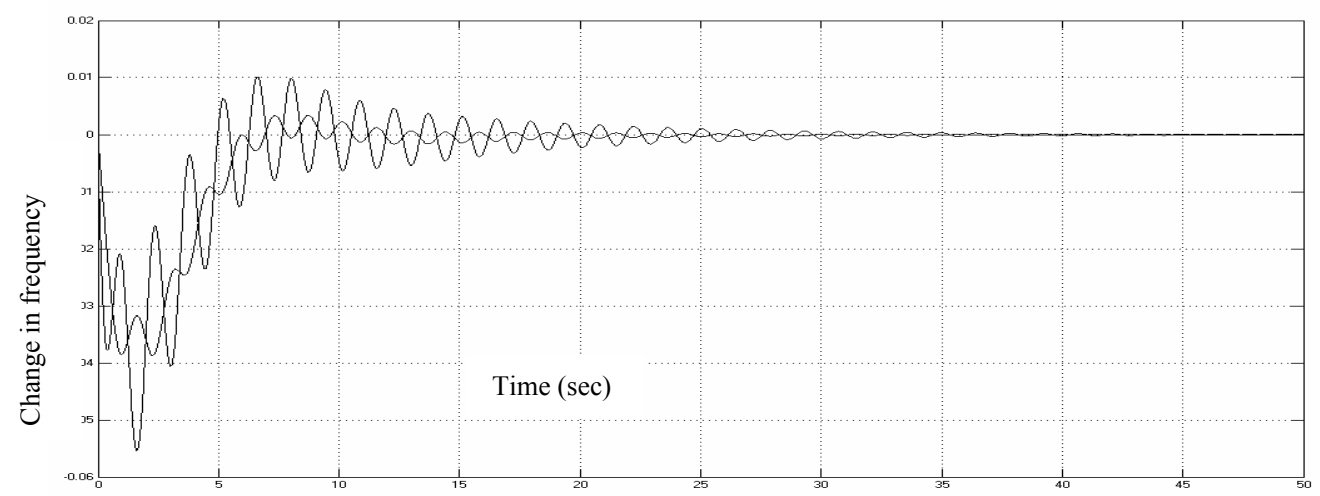

Fig. 13. Change in frequency (hydro-thermal plant) with ANN controller $(\Delta f)$.

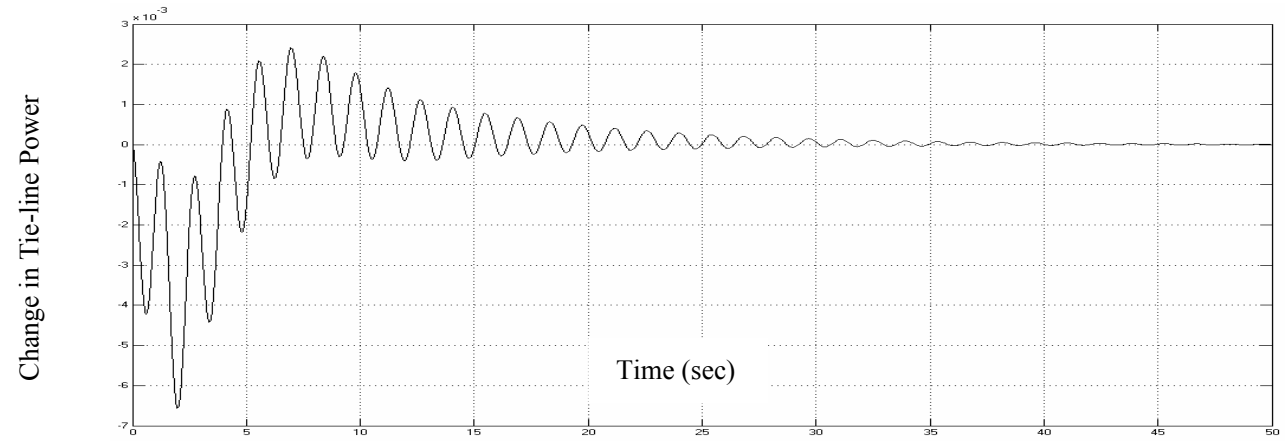

Fig.14 Change in Tie-line power (hydro-thermal plant) with ANN controller $\left(\Delta \mathrm{P}_{\text {tie }}\right)$

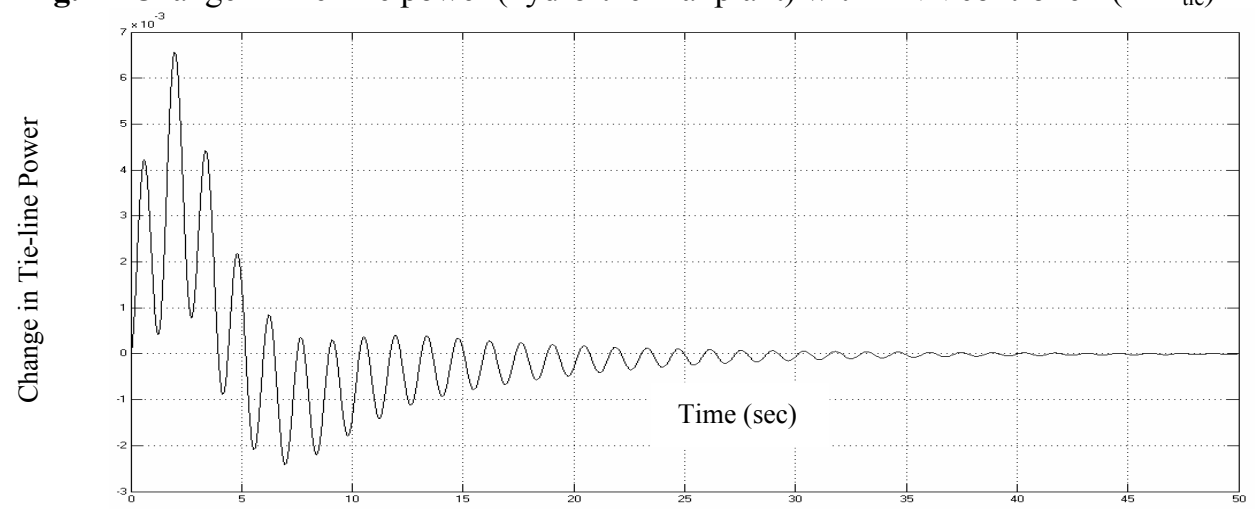

Fig.15 Change in Tie-line power (thermal plant) with ANN Controller $\left(\Delta \mathrm{P}_{\text {tie }}\right)$ 


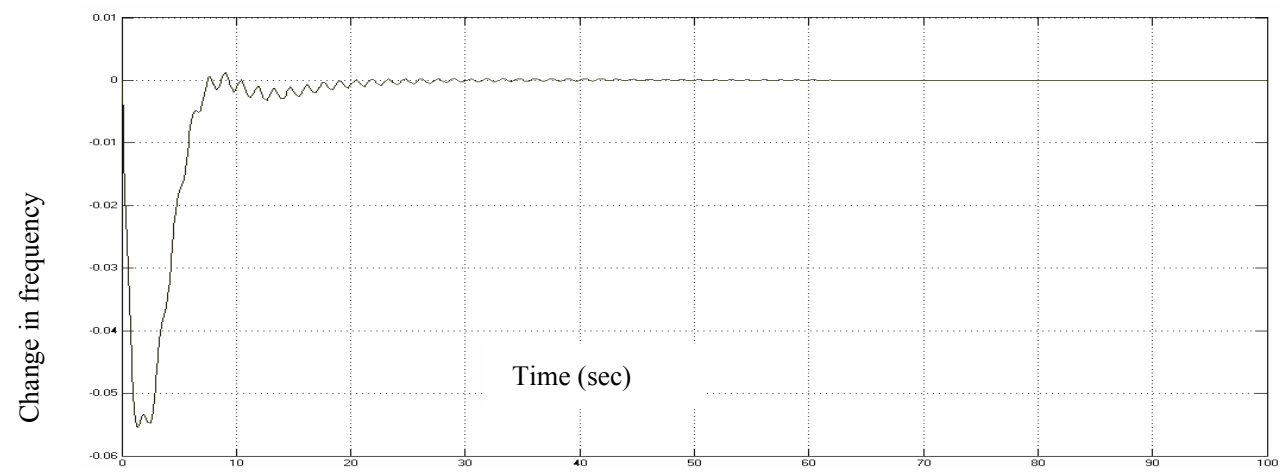

Fig.16. Change in frequency (Thermal plant) with PI controller $(\Delta f)$.

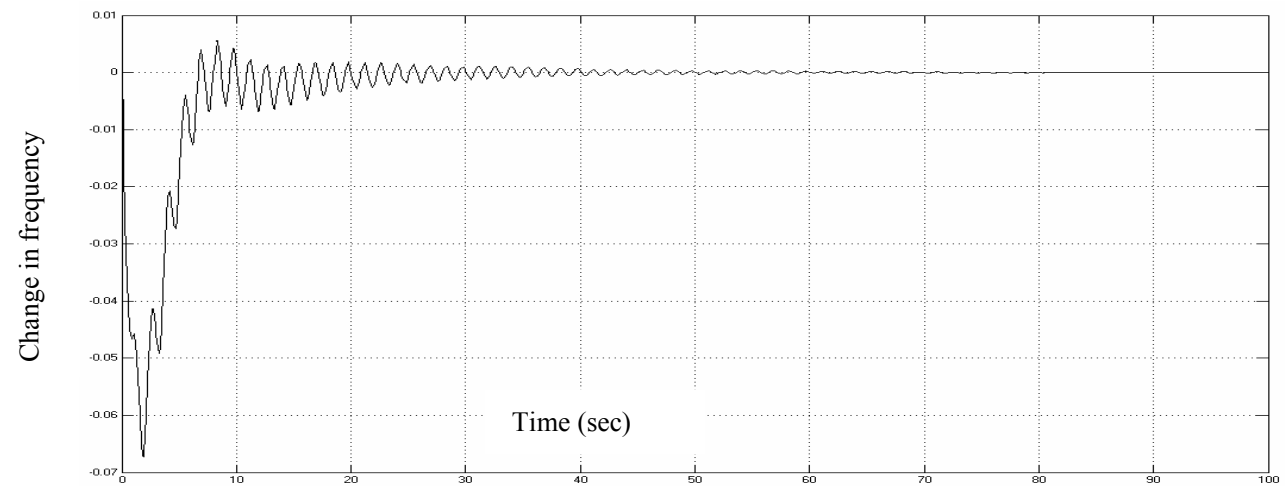

Fig.17. Change in frequency (hydro plant) with PI controller $(\Delta f)$.

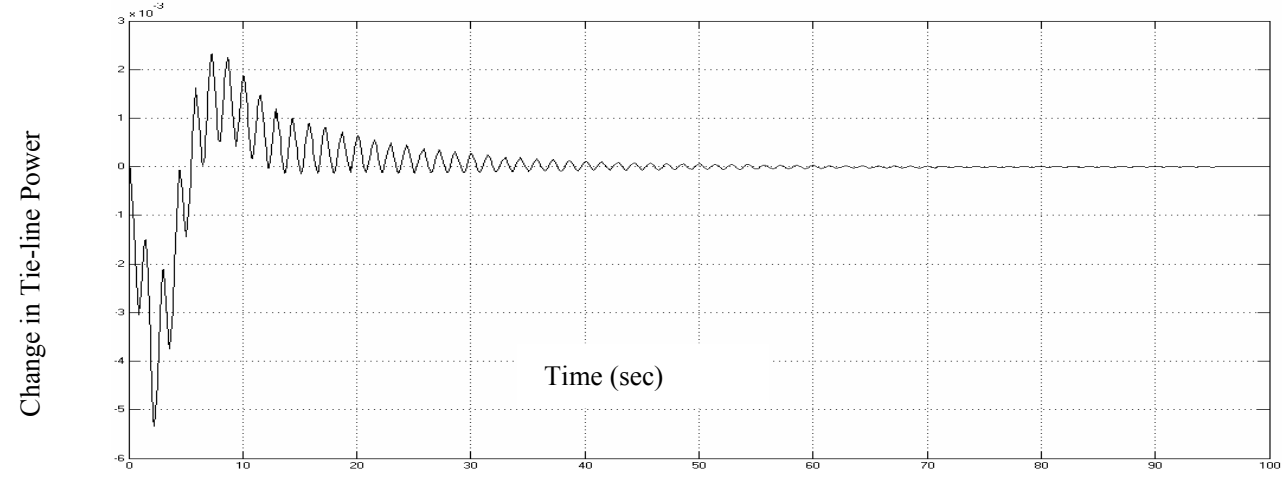

Fig.18. Change in Tie-line power (hydro-thermal plant) with PI controller $\left(\Delta \mathrm{P}_{\text {tie }}\right)$

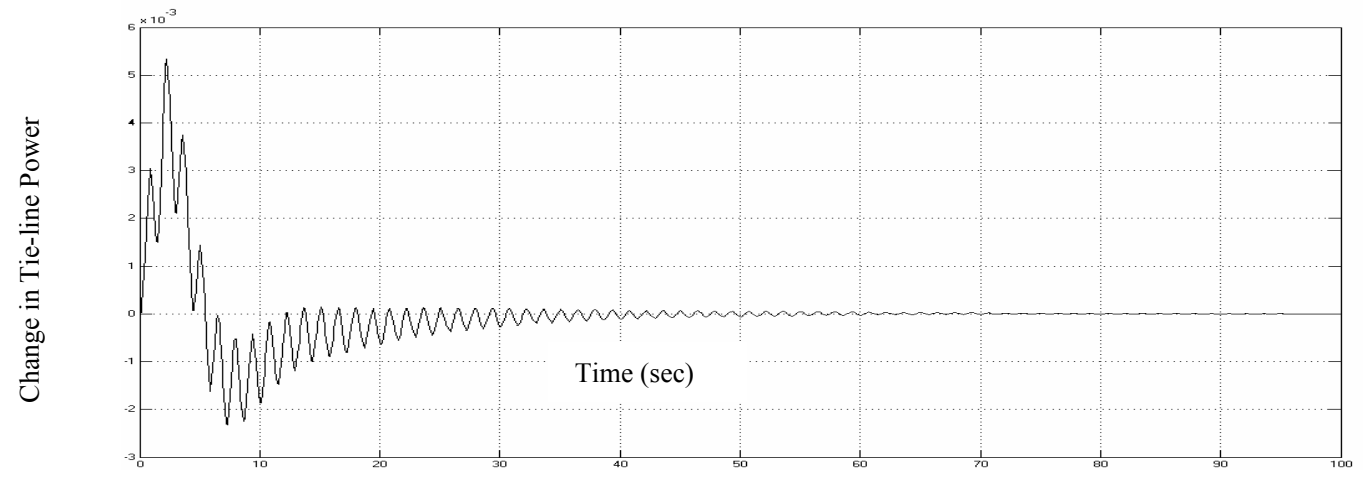

Fig.19. Change in Tie-line power (thermal plant) with PI controller $\left(\Delta \mathrm{P}_{\text {tie }}\right)$ 


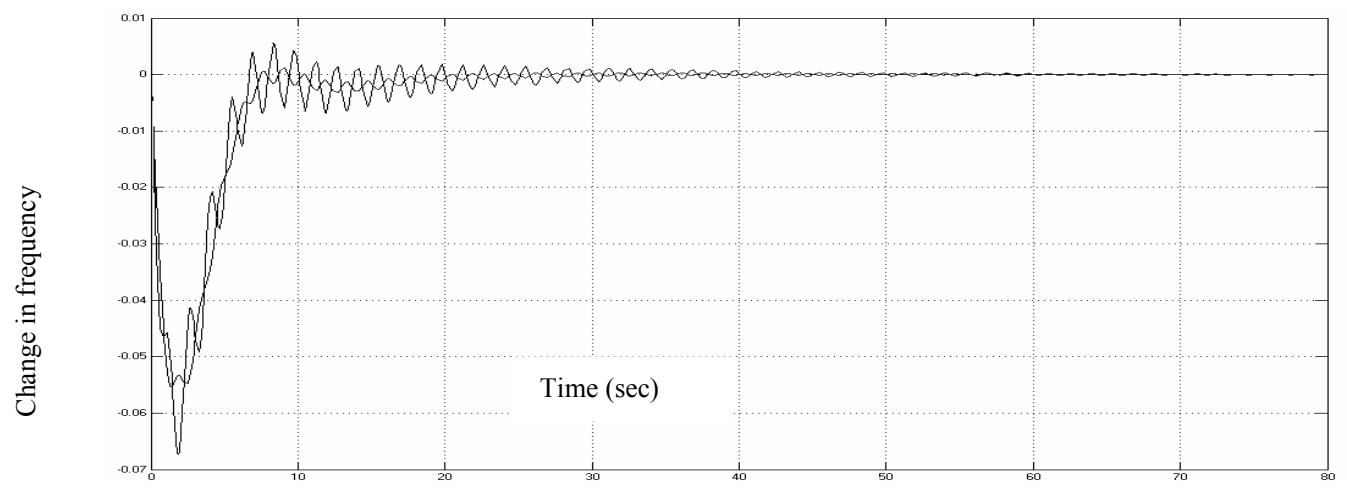

Fig.20. Change in frequency (hydro-thermal plant) with PI controller $(\Delta f)$.

By varying the load $1 \%$ in Hydro-Thermal Reheat three areas with PI controller, fuzzy controller and ANN controller, the steady state error is minimized to zero. Settling time and maximum peak overshoot in transient condition for both change in system frequency and change in tie-line power are given in table $2 \& 3$ respectively.

\section{Conclusions}

With $1 \%$ load variation in power system the following results are obtained. The conventional(PI) and Intelligent control approach (Fuzzy Controller and ANN controller) with inclusion of slider gain provides better dynamic performance and reduces the oscillation of the frequency deviation and the tie line power flow in each area in hydro-thermal combination of three area interconnected power system.

Table 2. Comparative Study of Settling Time

\begin{tabular}{|c|c|c|c|c|c|}
\hline Controllers & $\begin{array}{c}\Delta f \\
\text { Area 1 } \\
(\mathrm{sec})\end{array}$ & $\begin{array}{c}\Delta f \\
\text { Area 2 } \\
(\mathrm{sec})\end{array}$ & $\begin{array}{c}\Delta f \\
\text { Area 3 } \\
(\mathrm{sec})\end{array}$ & $\begin{array}{c}\Delta \mathrm{P}_{\text {tie }} \\
\text { Thermal- } \\
\text { thermal } \\
(\mathrm{sec})\end{array}$ & $\begin{array}{c}\Delta \mathrm{P}_{\text {tie }} \\
\text { Hydro- } \\
\text { thermal } \\
(\mathrm{sec})\end{array}$ \\
\hline Fuzzy & 50 & 50 & 50 & 50 & 50 \\
\hline ANN & 35 & 35 & 45 & 45 & 45 \\
\hline PI & 60 & 60 & 60 & 90 & 90 \\
\hline
\end{tabular}

Table 3. Comparative Study of Peak Overshoot

\begin{tabular}{|c|c|c|c|c|c|}
\hline Controllers & $\begin{array}{l}\Delta f \\
\text { Area 1 } \\
(\mathrm{pu})\end{array}$ & $\begin{array}{l}\Delta f \\
\text { Area } 2 \\
(\mathrm{pu})\end{array}$ & $\begin{array}{c}\Delta f \mathrm{Ar} \\
\text { ea } 3 \\
(\mathrm{pu})\end{array}$ & $\begin{array}{l}\Delta \mathrm{P}_{\text {tie }} \\
\text { Thermal- } \\
\text { thermal } \\
(\mathrm{pu})\end{array}$ & $\begin{array}{l}\Delta \mathrm{P}_{\text {tie }} \\
\text { Hydro- } \\
\text { thermal } \\
(\mathrm{pu})\end{array}$ \\
\hline Fuzzy & -0.071 & -0.071 & -0.080 & 0.033 & -0.033 \\
\hline ANN & -0.037 & -0.037 & -0.055 & 0.0065 & -0.0065 \\
\hline PI & -0.055 & -0.055 & -0.066 & -0.005 & 0.005 \\
\hline
\end{tabular}


Form the above table 2 and 3 it is clear that responses obtained, reveals that ANN controller with sliding gain provides better settling performance than Fuzzy and PI. Therefore, the intelligent control approach using ANN concept is more accurate and faster than the fuzzy control and conventional PI control scheme even for complex dynamical system.

\section{Nomenclature}

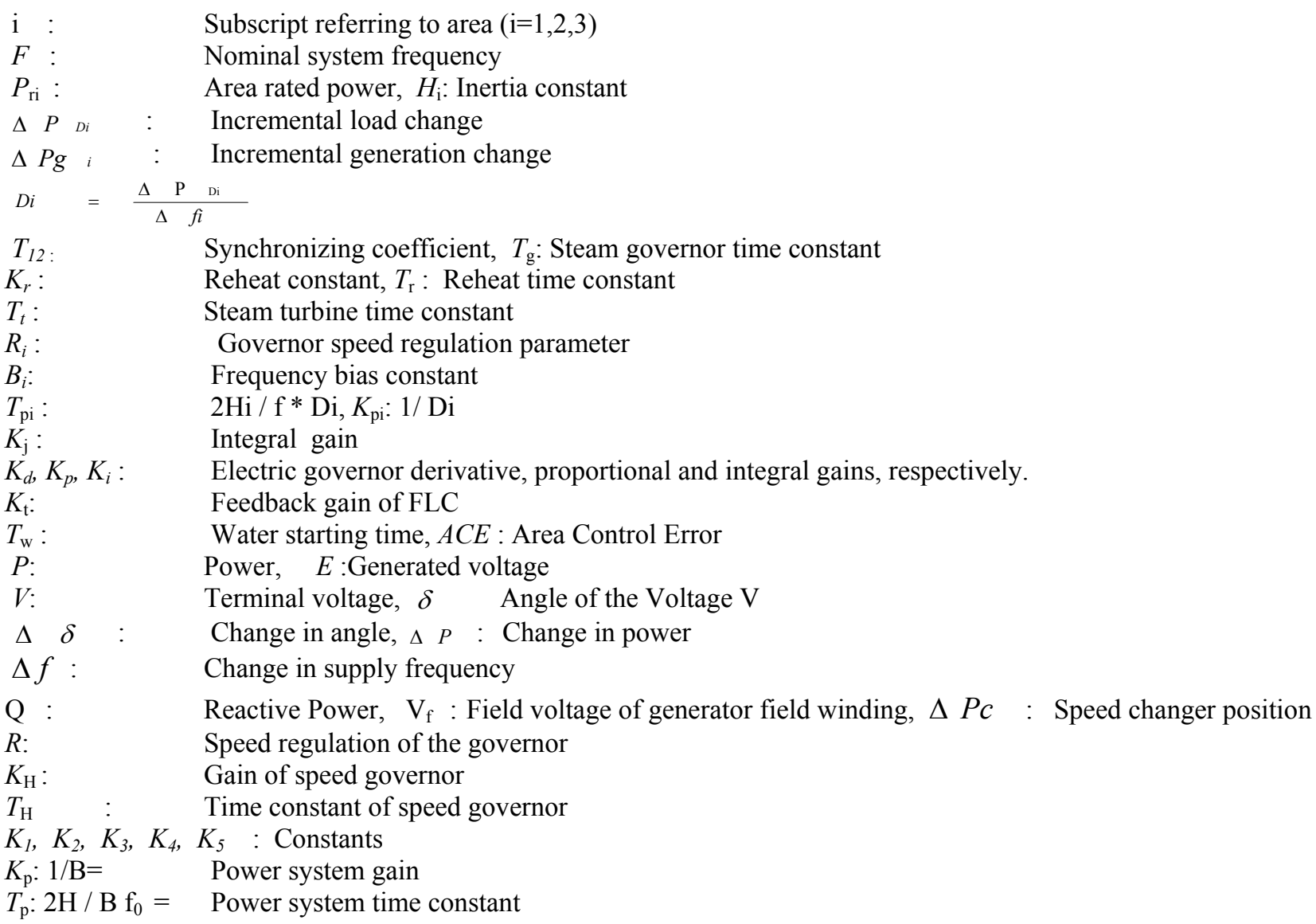

\section{Appendix}

Parameters are as follows:

$f=50 \mathrm{~Hz}, \mathrm{R}_{1}=\mathrm{R}_{2}=\mathrm{R}_{3}=2.4 \mathrm{~Hz} /$ per unit $\mathrm{MW}, \mathrm{T}_{\mathrm{g} 1}=\mathrm{T}_{\mathrm{g} 2}=0.08 \mathrm{sec}, \mathrm{T}_{\mathrm{p} 1}=\mathrm{T}_{\mathrm{p} 2}=\mathrm{T}_{\mathrm{p} 3}=20 \mathrm{sec} ; \mathrm{P}$ tie, $\max =200 \mathrm{MW} ; \operatorname{Tr}=10 \mathrm{sec}$; $\mathrm{Kr}=0.5, \mathrm{H}_{1}=\mathrm{H}_{2}=\mathrm{H}_{3}=5 \mathrm{sec} ; \mathrm{P}_{\mathrm{r} 1}=\mathrm{P}_{\mathrm{r} 2}=\mathrm{P}_{\mathrm{r} 3}=2000 \mathrm{MW}$

$\mathrm{T}_{\mathrm{t} 1}=\mathrm{T}_{\mathrm{t} 2}=0.3 \mathrm{sec} ; \mathrm{K}_{\mathrm{p} 1}=\mathrm{K}_{\mathrm{p} 2}=\mathrm{K}_{\mathrm{p} 3}=120$ Hz.p.u $/ \mathrm{MW} ; \mathrm{K}_{\mathrm{d}}=4.0 ; \mathrm{Ki}=5.0 ; \mathrm{Tw}=1.0 \mathrm{sec} ; \mathrm{D}_{1}=\mathrm{D}_{2}=\mathrm{D}_{3}=8.33 * 10^{-3}$ p.u MW/Hz.;

$\mathrm{B}_{1}=\mathrm{B}_{2}=\mathrm{B}_{3}=0.425$ p.u. MW/Hz; $\mathrm{a}_{1}=\mathrm{a}_{2}=\mathrm{a}_{3}=0.545 ; \mathrm{a}=2 * \mathrm{pi}^{*} \mathrm{~T}_{12}=2 * \mathrm{pi}^{*} \mathrm{~T}_{23}=2 * \mathrm{pi}^{*} \mathrm{~T}_{31}=0.545$ $\operatorname{delP}_{\mathrm{d} 1}=\operatorname{delP}_{\mathrm{d} 2}=\operatorname{delP}_{\mathrm{d} 3}=0.01$

\section{Acknowledgement}

This work is supported by Electrical \& Electronics Engineering Dept, Sam Higginbottom Institute of Agriculture, Technology \& Sciences- Deemed University, Allahabad, India. 


\section{References}

Anand B., Ebenezer A. Jeyakumar. 2009. Load frequency control with fuzzy logic controller considering non-linearities and boiler dynamics, ICGST-ACSE Journal, ISSN 1687-4811, Volume 8, issue 111, pp 15-20.

Aravindan P., Sanavullah M.Y. 2009. Fuzzy Logic Based Automatic Load Frequency Control of Two Area Power System With GRC, International Journal of Computational Intelligence Research, Volume 5, Number 1. pp. 37-44.

Chatterjee K. 2010. Design of Dual Mode PI Controller for Load Frequency Control, International Journal of Emerging Electric Power System. Vol. 11, Issue 4, Article 3.

Demiroren A., Zeynelgil H.L., Sengor N. S. 2001. The Application of ANN Technique to Load-frequency Control for Three- area Power System, IEEE Porto Power Tech Conference, PPT001, $10^{\text {th }}-13^{\text {th }}$ September2001, Porto, Portugal.

Elgerd O. I. 1971. Electric Energy System Theory; An Introduction, Mc Gro Hill.

Gayadhar-Panda, Sidhartha-Panda, Cemal Ardil. 2009. Automatic Generation Control of Interconnected Power System with Generation Rate Constraints by Hybrid Neuro Fuzzy Approach, World Academy of Science, Engineering \& Technology 52, pp543-548.

George-Gross, Lee J.W. 2001. Analysis of Load Frequency Control Performance Assessment Criteria, IEEE transaction on Power System, Vol. 16, No. 16, pp. 520-525.

Ha Q. P. 1998. A Fuzzy sliding mode controller for Power System Load Frequency Control. Second International Conference of Knowledge based Intelligent Electronic System, 21-23 April, Vol. 1, pp. 149-154.

Hykin S. 1994. Neural Network, Mac Miller NY.

Ibraheem, Kumar P., Kothari D.P., 2005. Recent Philosophies of Automatic Generation Control strategies in Power systems, IEEE Transaction on Power System Vol.20, No.1, pp-346-357.

John Y., Hung. 1993. Variable Structure Control: A Survey, IEEE Transaction on Industrial Electronics, Vol. 40, No.1.

Kothari D. P., Nagrath I.J., 2003. Modern Power System Analysis, Tata Mc Gro Hill, Third Edition.

Kumar A., Malik O.P., Hope G. S.1985. Variable-structure- system control applied to AGC of an interconnected power System, I.E.E.E. 1EE PROCEEDINGS, Vol. 132, Pt. C, No. 1 ,pp. 23-29.

Kundur P, 1994. Power System Stability and Control, Mc Graw hill New York.

Magla A., Nanda J. 2004. Automatic Generation Control of an Interconnected Hydro- Thermal System Using Conventional Integral and Fuzzy logic Control, In Proc. IEEE Electric Utility Deregulation, Restructuring and Power Technologies.(DRPT2004), Hong Kong, pp. 372-377.

Masiala M., Ghnbi M., Kaddouri A. 2004. An Adaptive Fuzzy Controller Gain Scheduling for Power System Load-Frequency Control, IEEE International Conference on Industrial Technology, (ICIT).pp.1515-1520.

Mines J. N. 1997. MATLAB Supplement to Fuzzy \& Neural approach in Engineering, John Wiley NY.

Nanda J., Kakkarum J.S. 2003. Automatic Generation Control with Fuzzy logic controllers considering generation constraints, In Proceeding of $6^{\text {th }}$ Int Conf on Advances in Power System Control Operation and managements" Hong Kong.

Ozkop Emre, H Ismail. Altas, M Adel. Sharaf. 2010. Load Frequency Control in Four Area Power Systems Using Fuzzy Logic PI Controller, 16th National Power Systems Conference, 15th-17th December, Department of Electrical Engineering, Univ. College of Engg., Osmania University, Hyderabad, A.P, India page No,233-236

Panna-Ram, Jha A.N. 2010. Automatic Generation control of interconnected hydro-thermal system in deregulated environment considering generation rate constraints, International Conference on Industrial Electronics, Control and Robotics, pp 148-158.

Ross T.J. 1995. Fuzzy logic with engineering application. Mc Gro Hill, International Edition.

Shayeghi H., Shayanfar H.A. 2004. Power system load frequency control using RBF neural network based on $\mu$-Synthesis theory, Proceeding of IEEE conference on cybernatics and intelligent system Singapore, 1-3 Dec 2004, pp 93-98.

Shayeghi H., Shayanfar H. A., Jalili A. 2009. Load frequency control strategies: A state-of-the- art survey for the researcher, Energy Conversion and Management 50, pp 344-353, ELSEVIER.

Surya-Prakash, Sinha S.K., Brijesh-Singh, Pandey A.S. 2009. Impact of slider gain on Load Frequency Control using Fuzzy Logic Controller, ARPN Journal of Engineering and Applied Science, Vol. 4, No 7.pp. 20-27.

Surya Prakash, Sinha S.K 2011. Application artificial intelligent in load frequency control of interconnected power system. International Journal of Engineering Science and Technology, Vol. 3, No. 4, pp. 264-275.

Surya Prakash, Sinha S K. 2010. Artificial Intelligent \& PI in Load frequency control of Interconnected Power system International Journal of Computer Science \& Emerging Technologies,( E-ISSN: 2044-6004), Volt 1,issue 4, pp.377-384.

Talaq J., Fadel A.l., Basri, 1999. Adaptive Fuzzy gain scheduling for Load Frequency Control, IEEE Transaction on Power System, Vol. 14. No.1, pp.145-150.

Wadhawa C.L., 2007. Electric Power System. New Age International Pub. 


\section{Biographical notes}

Surya Prakash Allahabad, 01.05.1971, Received his Bachelor of Engineering degree from The Institution of Engineers(India) in 2003, He obtained his M.Tech. in Electrical Engg.(Power System) from KNIT, Sultanpur.UP-India in 2009. Presently he is Pursuing Ph. D in Electrical Engg. (Power System). Working as Assistant Professor in SSET, SHIATS (Formerly Allahabad Agriculture Institute, Allahabad- India). His field of interest includes power system operation \& control, Intelligent control. Emai.1 ID : sprakashgiri0571@yahoo.com, sprakashgiri0571@gmail.com

Dr. S. K. Sinha belongs to Varanasi and his date of birth is $17^{\text {th }}$ Apr 1962. He received the B.Sc. Engg degree in Electrical from R.I.T. Jamshedpur, Jharkhand, India, in 1984, the M. Tech. degree in Electrical Engineering from Institute of Technology, B.H.U, and Varanasi, India in 1987, and the Ph.D. degree from IIT, Roorkee, India, in 1997. Currently he is working as Professor \& Head, Department of Electrical Engineering, Kamla Nehru Institute of Technology, Sultanpur, UP, India . His field of interest includes estimation, fuzzy control, robotics, and AI applications. E-mail: sinhask98@engineer.com

Received January 2012

Accepted February 2012

Final acceptance in revised form March 2012 